\title{
Detection of West Nile virus in six mosquito species in synchrony with seroconversion among sentinel chickens in India
}

\author{
Siraj A. Khan ${ }^{*}$, Purvita Chowdhury, Parveena Choudhury and Prafulla Dutta
}

\begin{abstract}
Background: West Nile virus (WNV) is a zoonotic flavivirus maintained in mosquito-bird transmission cycle. Although humans are accidental hosts, fatal outcomes following WNV infection have been reported from India. Studies have identified WNV as an important etiological agent causing acute encephalitis syndrome in Assam, Northeast India. While circulation of WNV is evident, the role of vectors and avian hosts involved in the transmission remains unclear. In this study we identified local mosquito species for evidence of WNV infection along with seroconversion among sentinel chickens.

Methods: Mosquitoes were collected and pooled species wise from June 2014 through December 2015. Virus was screened using reverse transcriptase PCR followed by sequencing and phylogenetic analysis. Sentinel chicken blood was screened for WNV antibody to assess their role in WNV transmission.

Results: A total of 52,882 mosquitoes belonging to 16 species were collected. WNV was detected in 18 pools of Culex vishnui, Culex tritaeniorhynchus, Culex quinquefasciatus, Culex whitmorei, Culex pseudovishnui and Mansonia uniformis. Phylogenetic analysis revealed that all mosquito derived sequences belonged to Lineage 5 and were $99-100 \%$ similar to the Assam strain of WNV isolated from human CSF sample in 2007. All sentinel chickens had seroconverted by the month of July that happens to be the peak WNV transmission month among humans as well.

Conclusion: To the best of our knowledge, this is the first report of WNV identification from field-collected $C X$. pseudovishnui and Mansonia uniformis in India. Our study demonstrates potential vectors which may play a crucial role in WNV transmission and should be considered in the vector control strategies. Additionally, our study highlights the role of sentinel chickens for WNV surveillance.
\end{abstract}

Keywords: West Nile virus, Lineage 5, Mosquito vectors, Culex pseudovishnui, Mansonia uniformis, Sentinel chickens

\section{Background}

West Nile virus (WNV) has emerged as one of the most widespread flavivirus being reported from all the continents except Antarctica [1]. Since its first outbreak in 1937, the disease attained immense attention during the mid-1990s corresponding to its severity, frequency and geographical expansion [2-4].

WNV is maintained naturally in an enzootic transmission cycle of mosquitoes (vectors) and birds (amplifying hosts) while humans, horses and other mammals serve

\footnotetext{
* Correspondence: sirajkhanicmr@gmail.com

Regional Medical Research Centre, NE Region, ICMR, Dibrugarh 786001, Assam, India
}

(c) The Author(s). 2017 Open Access This article is distributed under the terms of the Creative Commons Attribution 4.0 International License (http://creativecommons.org/licenses/by/4.0/), which permits unrestricted use, distribution, and reproduction in any medium, provided you give appropriate credit to the original author(s) and the source, provide a link to the Creative Commons license, and indicate if changes were made. The Creative Commons Public Domain Dedication waiver (http://creativecommons.org/publicdomain/zero/1.0/) applies to the data made available in this article, unless otherwise stated. quitoes involved in epizootic and epidemic transmission including species of Anopheles (in USA, Isreal, Madagascar), Aedes (in Africa, Russia, USA), Mansonia (Africa) and Ochlerotatus (USA), the most important vectors of WNV represent Culex spp. [5]. In India, WNV has been isolated from $C x$. vishnui, $C x$. quinquefasciatus, $C x$. tritaeniorhynchus and $C x$. fatigans [6]. House sparrows and corvids have been implicated as important WNV reservoirs in North America, Europe and Africa. However, in the Indian subcontinent, ardeid birds are thought to be the possible amplifying hosts [7]. 
WNV infection in humans can induce symptoms ranging from febrile fever to severe neurological syndromes like encephalitis, meningitis and paralysis [8]. In India, WNV-neutralizing antibodies were first detected in 1952 [9]. Since then, the virus has been isolated from different hosts and regions of the country. Recognition of WNV among acute encephalitis syndrome causing etiologies in Assam in 2006 was the first report of the flavivirus from eastern region of India [10]. Genetic characterization of two WNV isolates obtained from this region revealed similarity with south Indian WNV Lineage 5 strains [11]. Although WNV circulation in this region is evident, adequate knowledge of vectors and amplifying hosts involved in transmission of WNV are lacking. In this study we investigated local mosquito species as candidate WNV vectors along with the role of birds as amplifying hosts.

\section{Methods}

\section{Study sites}

Study sites were selected based on maximum number and frequency of WN cases reported during earlier outbreaks in the eastern regions of the State of Assam. Adult mosquitoes were collected from four townships: Dibrugarh $\left(27.4728^{\circ} \mathrm{N}\right.$, $\left.94.9120^{\circ} \mathrm{E}\right)$; Tinsukia $\left(27.4922^{\circ} \mathrm{N}, \quad 95.3468^{\circ} \mathrm{E}\right)$; Sivasagar $\left(26.9826^{\circ} \mathrm{N}, 94.6425^{\circ} \mathrm{E}\right)$; and Duliajan $\left(27.3572^{\circ} \mathrm{N}, 95.3223^{\circ}\right.$ E) (Fig. 1). The sites were kept unchanged throughout the study. The selected townships have numerous water bodies that serve as abodes for migratory birds during winters.

\section{Entomological study}

Mosquito collection was carried out for $1-2 \mathrm{~h}$ during dusk using mechanical aspirators at fortnightly intervals from June 2014 through December 2015. Mostly cattle sheds were targeted which are open on three sides with a close proximity to human dwellings. All mosquitoes were identified following standard entomological keys [12-14] under immobilization (by cold shock) and pooled species wise for incrimination studies. Although we did not calculate the proportionate ratio, it comprised of non-fed, partially-fed as well as fully-fed mosquitoes. However, the fully-fed ones were kept in the insectarium for over $24 \mathrm{~h}$ for digestion of the blood meal before identification and pooling. Species wise mosquito man hour density (MHD) was calculated as

$\mathrm{MHD}=$ number of mosquitoes collected $\times 60 /$ time spent in minutes $\times$ number of persons involved in collections.

\section{Molecular analysis}

Every mosquito pool was triturated mechanically using $2 \%$ foetal bovine serum (FBS) (Gibco, Thermo Fisher Scientific, Massachusetts, USA) in pre chilled minimum essential medium (MEM) (Sigma-Aldrich, St. Louis, MO, USA) treated with $50 \mathrm{U}$ penicillin (Sigma-Aldrich, St. Louis, $\mathrm{MO}$, USA), $50 \mu \mathrm{g} / \mathrm{ml}$ streptomycin (Sigma-Aldrich, St. Louis, MO, USA), and $50 \mu \mathrm{g} / \mathrm{ml}$ amphotericin B (SigmaAldrich, St. Louis, MO, USA). The homogenate after centrifugation was processed for RNA extraction as per manufacturer's instructions (QIAamp Viral RNA Kit, Qiagen, Germany).

Presence of WNV RNA was screened in all the mosquito pools using a semi-nested reverse transcriptase (RT)-PCR performed on verity 96 well thermal cycler (Applied Biosystems, California, USA). Primers used for WNV RNA amplification have been described by Khan et al. [15] giving a 500 bp product. Briefly, the first round of amplification was performed with $2 \mu \mathrm{l}$ of re-

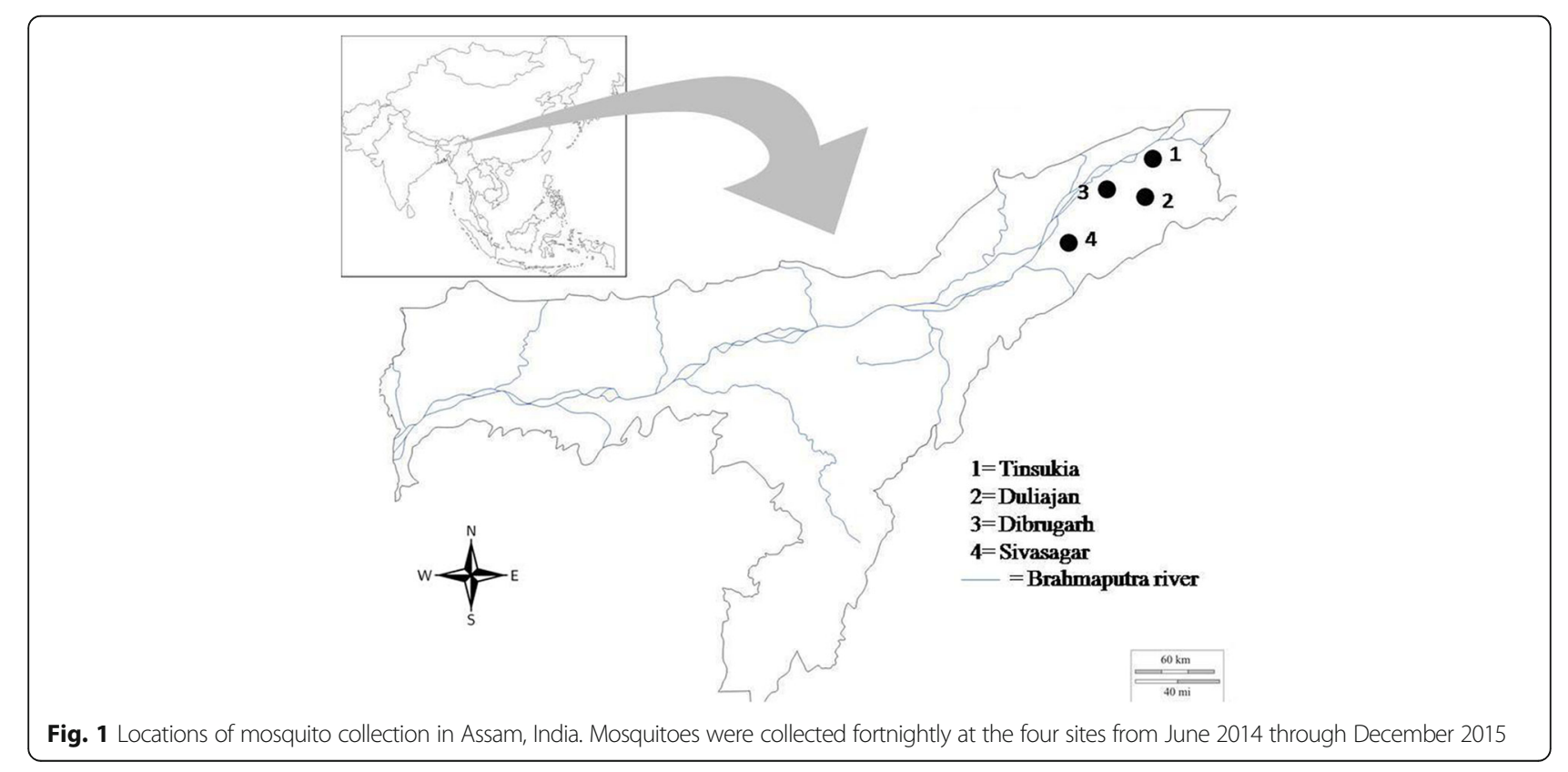


suspended RNA template using Access one step RT-PCR kit (Promega, Wisconsin, USA). The first PCR amplicon $(1 \mu \mathrm{l})$ was then subjected to semi nested PCR using $2 \times$ Master Mix (Promega, Wisconsin, USA) with 200nM of reverse primer (sn5'-TGG CCA AGA ACA CGA CCA GAA GG-3') in a final volume of $15 \mu \mathrm{l}$. PCR profile for the second round of amplification were carried out by denaturing at $94{ }^{\circ} \mathrm{C}$ for $5 \mathrm{~min}$, followed by 35 cycles of $94{ }^{\circ} \mathrm{C}$ for $30 \mathrm{~s}, 54{ }^{\circ} \mathrm{C}$ for $1 \mathrm{~min}$ and $72{ }^{\circ} \mathrm{C}$ for $1 \mathrm{~min}$ and final extension at $72{ }^{\circ} \mathrm{C}$ for $7 \mathrm{~min}$. All positive amplicons were confirmed by sequencing commercially (Avantor, Selangor, Malaysia).

\section{Phylogenetic analysis}

The resulting forward and reverse sequences were manually edited in BioEdit version 7.0.9 software [16]. The edited nucleotide sequences were compared with a total of $20 \mathrm{WNV}$ GenBank sequences which were selected on the basis of their lineage and geographical origin for determination of WNV lineage. A GenBank sequence (AF080251) of Indian Japanese encephalitis virus (JEV) strain was used as the out-group. Phylogenetic analysis was carried out using Mega 7 software [17]. The Clustal W program implemented in Mega 7 software was used to generate a multiple alignment of the sequences and subsequently construct character based maximum likelihood (ML) tree. Nucleotide and amino acid sequence similarity was estimated in Mega 7 using the gamma distribution (shape parameter $=5$ ). Reliability of the tree was estimated by 1000 bootstrap replications.

\section{Avian study}

In cooperation with the Forest Department, Government of Assam, India, a strict vigilance on any unusual mortality of birds in the reserve forests and national parks of Assam was maintained. However, no such incidence (either among migratory or local birds) was reported during the study period. Subsequently, we attempted to look for WNV seroconversion in sentinel chickens to ascertain the role of domestic birds in WNV transmission as circulation of WNV has been evident among humans in this region for the past decade [10]. Sentinel chickens with each flock consisting of 10 birds were established at two of the study sites, Dibrugarh and Sivasagar, during April 2015 - August 2015. Blood samples were collected fortnightly by using brachial venipuncture method, and the separated serum was stored at $-80{ }^{\circ} \mathrm{C}$ until serological tests were performed.

\section{Serological analysis}

To detect WNV-specific antibodies, chicken serum samples were tested in 96 well microtitre plates using hemagglutination inhibition (HI) test [18]. Briefly, removal of nonspecific inhibitors in chicken sera was achieved by acetone extraction. Acetone treated chicken sera were serially diluted and mixed with four hemagglutination (HA) units of WNV antigen. Following an overnight incubation at $4{ }^{\circ} \mathrm{C}$, goose red blood corpuscles (RBCs) were added and the solution was incubated at room temperature for another hour. The HI titre was expressed as the highest serum dilution producing complete inhibition of RBC agglutination. Sera with HI titre of 1:10 were considered as positive. Due to crossreactivity among JEV and WNV in endemic region, the chicken sera were also tested against JEV antigen. Consequently, WNV antibodies were distinguished by comparing both WNV and JEV HI titres [19].

\section{Statistical analysis}

The minimum infection rate (MIR) was calculated as the number of infected mosquitoes per 1000 mosquitoes tested [20]. Differences in chicken seroprevalence rates among the two study sites were tested by unpaired Student's $t$-test. The temporal concordance of sentinel chicken seroconversion and mosquito MHD was evaluated by cross correlation analysis.

\section{Results \\ Mosquito samples and viral detection}

During June 2014 - December 2015, a total of 52,882 adult mosquitoes belonging to 16 species (including 10 known potential vectors of WNV) were collected and analysed. Our collections showed an almost equal distribution of mosquito density in all the study sites and the total number of samples per site is given in Table 1 . Mansonia uniformis, Culex vishnui and Culex tritaeniorhynchus were the predominant species constituting $26.32,24.47$ and $13.50 \%$ of the total catch, respectively. Eighteen of the 1392 mosquito pools tested RT-PCR positive for WNV non-structural 1 (NS1) gene. Majority of the positive pools consisted of Ma. uniformis and $C x$. vishnui followed by $C x$. tritaeniorhynchus, $C x$. quinquefasciatus, Cx. pseudovishnui and Cx. whitmorei (Table 2). The MIR of $C x$. whitmorei was found to be highest.

\section{Phylogenetic analysis}

Partial sequence of WNV NS1 region of .500 bp was obtained from 18 mosquito pools (GenBank Accession nos. KX646169-KX646186). The derived phylogenetic tree revealed that the sequences obtained during the study formed a clade within the Lineage 5 in the tree (Fig. 2). Furthermore, it indicated that the circulating WNV in Assam during 2014-2015 was similar to the Lineage 5 strain isolated in Assam during 2007 (HQ246154). An additional file shows that all the WNV positive sequences were more than 99\% similar to the 2007 Assam isolate (see Additional file 1: Table S1). The mean genetic distance of $0.01 \%$ was found at the nucleotide level. On alignment of each mosquito- 
Table 1 Distribution of adult mosquitoes of sixteen species collected at the four study sites

\begin{tabular}{|c|c|c|c|c|}
\hline Species/ Study site & Dibrugarh & Tinsukia & Duliajan & Sivasagar \\
\hline Aedes albopictus ${ }^{a}$ & 4 & 430 & 0 & 0 \\
\hline Aedes nigrostriatus & 2 & 29 & 28 & 73 \\
\hline Aedes. vexans ${ }^{a}$ & 2 & 64 & 0 & 0 \\
\hline Anopheles annularis & 124 & 175 & 60 & 319 \\
\hline Anopheles hyrcanus ${ }^{a}$ & 480 & 114 & 379 & 639 \\
\hline Anopheles vagus & 137 & 35 & 50 & 114 \\
\hline Armigeres kuchingensis & 350 & 283 & 308 & 242 \\
\hline Culex fuscocephala & 34 & 65 & 150 & 163 \\
\hline Culex gelidus $^{\mathrm{a}}$ & 0 & 0 & 70 & 7 \\
\hline Culex pseudovishnui ${ }^{a}$ & 1453 & 1512 & 1365 & 1147 \\
\hline Culex quinquefasciatus $^{a}$ & 1380 & 838 & 1540 & 262 \\
\hline Culex tritaeniorhynchus $^{\mathrm{a}}$ & 1925 & 1573 & 1816 & 1822 \\
\hline Culex vishnui ${ }^{\mathrm{a}}$ & 3033 & 3413 & 4027 & 2470 \\
\hline Culex whitmorei $^{a}$ & 599 & 1598 & 500 & 404 \\
\hline Mansonia annulifera & 136 & 649 & 226 & 342 \\
\hline Mansonia uniformis ${ }^{\mathrm{a}}$ & 2819 & 2566 & 4509 & 4028 \\
\hline Total & 12,478 & 13,344 & 15,028 & 12,032 \\
\hline
\end{tabular}

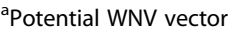

derived sequence with 2005 Indian strain (DQ256376) and 2007 Assam strain (HQ246154), a few synonymous and non-synonymous mutations were observed. Interestingly, two synonymous mutations, i.e. $\mathrm{C} \rightarrow \mathrm{T}$ and $\mathrm{T} \rightarrow \mathrm{G}$, were found in all mosquito sequences except for KX646169. Moreover, two nucleotide substitutions resulted in changes in amino acid codons, i.e. from valine to alanine in three mosquito-derived sequences. It is worth mentioning that one of the sequences (KX646186) formed a distinct subclade pertaining to a few synonymous and nonsynonymous substitutions.

\section{Serological analysis}

It was observed that $70 \%$ of the chicken sera had higher WNV compared to JEV HI titer. Seroconversion in sentinel chickens started towards end of May and antibodies against WNV were detected in all sentinel chicken by
July 2015. Significant differences in seroprevalence rates among the two study sites were not observed in the present study. The percentage of chicken seroconversion during May to August 2015 was compared with the abundance of incriminated WNV vectors. Chicken seroconversion peak coincided with the increase in abundance of three incriminated WNV vectors, $M a$. uniformis, $C x$. vishnui and $C x$. whitmorei. However, peaks in abundance of $C x$. pseudovishnui and $C x$. tritaeniorhynchus were preceded by peaks in chicken seroconversion. The cross correlation with $95 \%$ CI revealed that sentinel chicken seroconversion $(r=0.77, P=0.06)$ was marginally associated to the density of $M a$. uniformis mosquito after 2 weeks (Fig. 3).

\section{Discussion}

The present study detected WNV belonging to Lineage 5 from six species of mosquitoes and corroborated that the transmission of WNV involves bird-mosquito cycle in upper basins of the Brahmaputra valley of Assam, Northeast India. The geographical distribution and abundance of potential WNV vectors at all of the four study sites suggests the possibility of active circulation of WNV. Cattle sheds targeted during mosquito collection harbor abundant zoophilic mosquito species. As almost all the potential/incriminated vector species are exophilic and exophagic in nature, it is unlikely that important mosquito species could have been missed. As anticipated, Ma. uniformis and $C x$. vishnui subgroup were highly abundant in the study areas similar to previous study conducted by Khan et al. [21]. These species happen to be established JEV vectors as well, which may explain the concurrent outbreaks of WNV and JEV in this region. An earlier study has also evidenced coinfection of both WNV and JEV in humans from this region during outbreaks in 2007 [15].

As sentinel chickens do not produce transmissible viremia, molecular analysis was not performed for the sampled chicken sera. However, molecular analysis of mosquito pools revealed WNV in Ma. uniformis, $C x$. vishnui, $C x$. tritaeniorhynchus, $C x$. quinquefasciatus, $C x$. pseudovishnui and $C x$. whitmorei. The role of Culex

Table 2 Mosquito species found to be WNV-positive by RT-PCR and sequencing from the four study sites

\begin{tabular}{|c|c|c|c|c|c|}
\hline \multirow[t]{2}{*}{ Species } & Dibrugarh & Tinsukia & Duliajan & Sivasagar & \multirow[t]{2}{*}{ MIR } \\
\hline & Positive/Pools tested & Positive/Pools tested & Positive/Pools tested & Positive/Pools tested & \\
\hline Cx.pseudovishnui & $0 / 36$ & $0 / 27$ & $0 / 35$ & $2 / 29$ & 0.36 \\
\hline Cx. quinquefasciatus & $2 / 44$ & $0 / 30$ & $0 / 41$ & $0 / 13$ & 0.49 \\
\hline Cx. tritaeniorhynchus & $1 / 44$ & $1 / 38$ & $1 / 46$ & $0 / 41$ & 0.42 \\
\hline Cx. vishnui & $0 / 67$ & $1 / 90$ & $0 / 85$ & $4 / 57$ & 0.38 \\
\hline Cx. whitmorei & $1 / 21$ & $0 / 47$ & $0 / 21$ & $0 / 15$ & 0.55 \\
\hline Ma. uniformis & $2 / 71$ & $0 / 66$ & $2 / 101$ & $1 / 89$ & 0.35 \\
\hline
\end{tabular}

Abbreviation: MIR minimum infection rate; calculated as (number of positive pools/total number of specimen tested) $\times 1000$ 


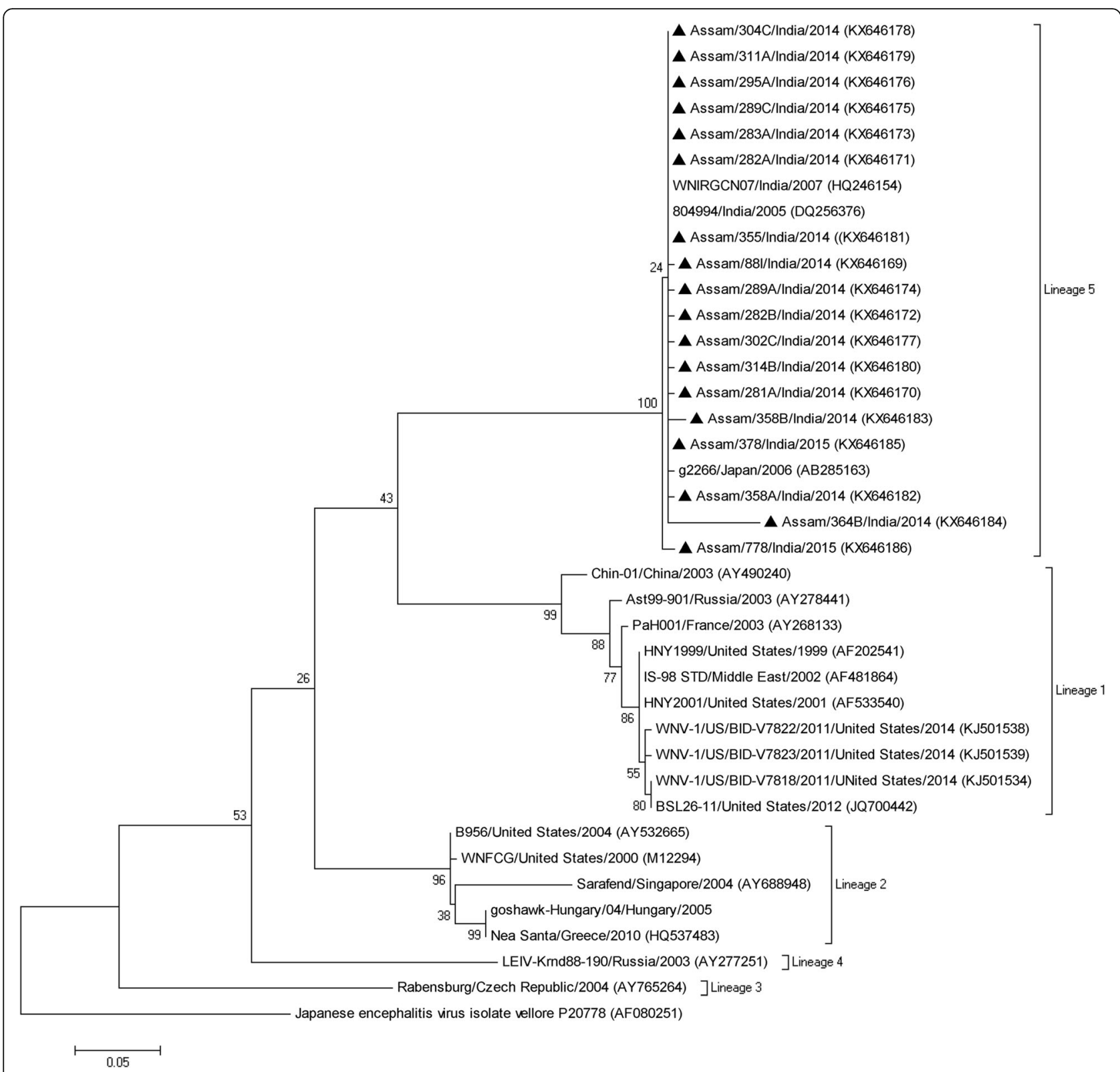

Fig. 2 Phylogenetic analysis of geographically distinct West Nile virus sequences based on 500 bp region of the NS1 gene. Black triangles denote the mosquito-derived sequences from this study. The maximum likelihood tree was constructed using Kimura 2-parameter model in Mega 7. An Indian strain (P-20778) of Japanese encephalitis virus (GenBank accession no. AF080251) was used as an outgroup. Node values were estimated for 1000 replicates

species, especially $C x$. quinquefasciatus have been well documented and implicated in WNV transmission in North America, Europe, South Africa and Australia [22]. In India, WNV has been isolated from $C x$. vishnui during 1955-1958 and 1980-1981, and from Cx. whitmorei and Cx. tritaeniorhynchus in 1980. Mansonia uniformis have been found to carry WNV in Madagascar and Ethiopia $[23,24]$. However, our study describes the first report of Ma. uniformis as a potential WNV vector in India. On the other hand, field-collected $C x$. pseudovishnui has never been incriminated for WNV infection, although, a few experimental studies implied it to be a candidate WNV vector $[25,26]$. Our study provides evidence that $C x$. pseudovishnui is a potential vector for WNV transmission in this region. The incriminated mosquito species in our study are known as zoo-anthropogenic [27, 28]. Blood meal analysis of $C x$. quinquefasciatus has demonstrated it to be highly ornithophilic besides feeding on mammals [29]. It is most likely that that this vector acts as an important bridge vector and aid in viral amplification. 


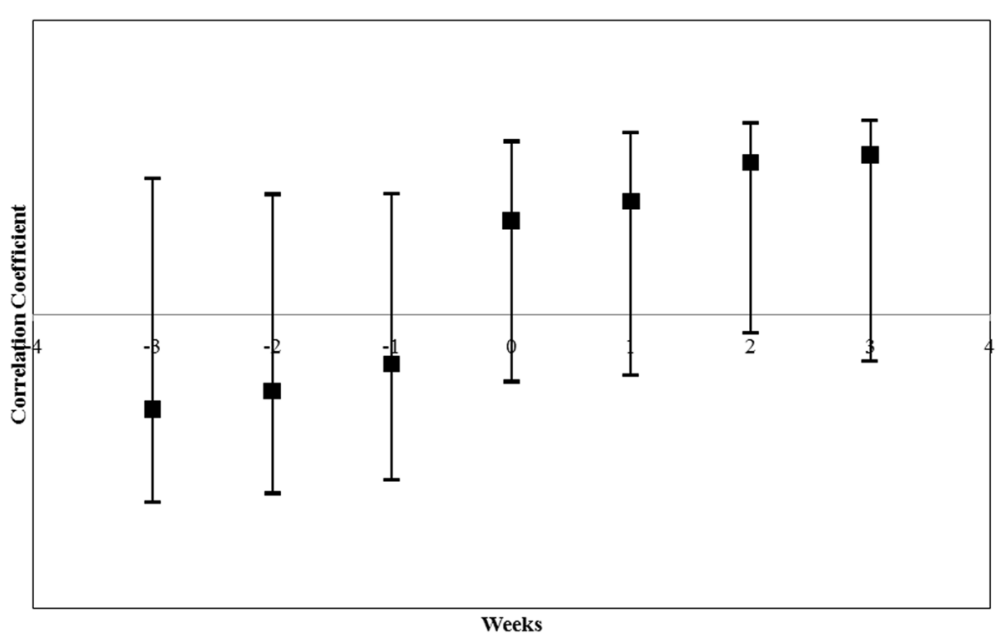

Fig. 3 Relationship between Ma. uniformis MHD and lagged sentinel chicken seroconversion (lead and lag shown on the x-axis) represented by correlation coefficient with $95 \%$ confidence interval

Phylogenetic analysis revealed that all the sequences belonging to WNV Lineage 5 are similar to earlier report of WNV from Assam, India [11]. Based on isolates obtained from mosquitoes and humans in previous studies, there has been a prominent circulation of WNV Lineage 5 in India since its first detection in 1955 [30]. In our study, a distinct clade formed between the sequences from mosquitoes (2014-2015) and a WNV isolate from humans (2007) in Assam. This indicates a local circulation of this particular strain of Lineage 5 $\mathrm{WNV}$ in the given situation. However, the implications of synonymous and non-synonymous mutations observed in WNV strain in mosquito species require further studies.

The hemagglutination inhibition (HI) test used in this study has been considered as one of the standards for measuring neutralizing antibody titre. Previous studies have demonstrated the test to be specific as well as sensitive which is comparable to micro virus neutralization test [31]. Serological evidence of WNV infection in wild resident birds has been previously observed in Northern and Eastern India [32]. In this study, WNV antibodies were observed in sentinel chickens during the monsoon season: May-July, which is conducive for increase of potential vectors in this region. Although seroconverted chickens were not replaced with naïve ones and a low number of sentinel chicken were considered in this study, it indicated local WNV transmission that may be employed as an indicator of WNV activity in this region. The use of sentinel chicken to monitor WNV activity has been widely incorporated in many countries with WNV transmission including USA [33]. However, the involvement of other domestic birds of this region needs to be further investigated as earlier reports have shown WNV seroprevalence in domestic ducks and turkey $[24,34]$. Wild migratory birds are often seen in this region, visiting water bodies and the banks of Brahmaputra, which is $10-15 \mathrm{~km}$ from all the study sites. Future studies involving sampling from migratory and other domestic birds may elucidate their role in the WNV transmission in this region.

\section{Conclusion}

Our study found two new potential WNV vectors that could be playing a crucial role in WNV transmission in India. Detailed virus transmission studies as well as blood meal analysis of incriminated mosquito vectors would provide more evidence of the WNV cycle. Additionally, we corroborated that sentinel chickens can be useful to monitor WNV activity. These findings expand our understanding on vector diversity of WNV and help expedite future studies on the eco-epidemiology of WNV transmission.

\section{Additional file}

Additional file 1: Table S1. Nucleotide divergence among WNV Lineage 5 sequences. (XLSX $10 \mathrm{~kb}$ )

\section{Abbreviations}

HA: Hemagglutination; HI: Hemagglutination inhibition; JEV: Japanese encephalitis virus; ML: Maximum likelihood; NS1: Non-structural 1; RBC: Red blood corpuscles; RT-PCR: Reverse transcriptase polymerase chain reaction; WNV: West Nile virus

\section{Acknowledgements}

The authors thank the entire arbovirology division of Regional Medical Research Centre, NE Region, Dibrugarh. The authors are also grateful to Nibedita Das, Dipjyoti Baruah, Pranab Saikia and Pranjal Mahanta for their excellent technical support.

\section{Funding}

This study was supported by Indian Council of Medical Research, New Delhi, India. The funding agency did not have any role in study design, collection, analysis and preparation of the manuscript. 


\section{Availability of data and materials}

All data generated or analysed during the current study are included in this article and its Additional file. The sequences are submitted in the GenBank database under accession numbers KX646169-KX646186.

\section{Authors' contributions}

SAK and PD designed and planned the study. Purvita Chowdhury and Parveena Choudhury performed the laboratory work and analyzed the data. SAK and Purvita Chowdhury drafted the manuscript. All authors read and approved the final manuscript.

\section{Competing interests}

The authors declare that they have no competing interests.

\section{Consent for publication}

Not applicable.

\section{Ethics approval}

The study was approved by the Institutional Ethics Committee of Regional Medical Research Centre, ICMR, Dibrugarh, Assam, India and sampling was carried out by trained personnel.

\section{Received: 13 September 2016 Accepted: 21 December 2016}

Published online: 07 January 2017

\section{References}

1. HayesCG. West Nile fever. In: Monath TP, editor. The arboviruses: epidemiology and ecology, Vol. V. Boca Raton (FL): CRC Press;1989. p. 59-88

2. Smithburn KC, Hughes TP, Burke AW, Paul JH. A neurotropic virus isolated from the blood of a native of Uganda. Am J Trop Med. 1940;20:471-92.

3. Tsai TF, Popovici F, Cernescu C, Campbell GL, Nedelcu NI. West Nile encephalitis epidemic in southeastern Romania. Lancet. 1998;352(9130):767-71.

4. Weinberger M, Pitlik SD, Gandacu D, Lang R, Nassar F, David DB, et al. West Nile fever outbreak, Israel, 2000: epidemiologic aspects. Emerg Infect Diseases. 2001;7(4):686

5. Wildpro-the electronic encyclopaedia and library for wildlife. Wildlife Information Network, Warwickshire, UK. 2013. http://wildpro.twycrosszoo. org/S/virus/flaviviridae/Flaviviridae_WNVirus/06WNVSpplntermediateHost. htm. Accessed 11 Dec 2015.

6. Paramasivan R, Mishra AC, Mourya DT. West Nile virus: the Indian scenario. Indian J Med Res. 2003:118:101-8.

7. Rodrigues FM, Guttikar SN, Pinto BD. Prevalence of antibodies to Japanese encephalitis and West Nile viruses among wild birds in the Krishna-Godavari Delta, Andhra Pradesh, India. Trans R Soc Trop Med Hyg. 1981;75(2):258-62.

8. Komar N. West Nile viral encephalitis. Revue scientifique et technique (International Office of Epizootics). 2000;19(1):166-76.

9. Banker DD. Preliminary observations on antibody patterns against certain viruses among inhabitants of Bombay city. Indian J Med Sci. 1952;6:733-46.

10. Khan SA, Dutta P, Khan AM, Chowdhury P, Borah J, Doloi P, Mahanta J. West Nile virus infection, Assam, India. Emerg Infect Diseases. 2011;17(5):946-8.

11. Chowdhury P, Khan SA, Dutta P, Topno R, Mahanta J. Characterization of West Nile virus (WNV) isolates from Assam, India: insights into the circulating WNV in northeastern India. Comp Immunol Microbiol Infect Dis. 2014;37(1):39-47.

12. Barraud PJ. The fauna of British India, including Ceylon and Burma. Diptera. Volume V. Family Culicidae. Tribes Megarhinini and Culicini. London: Taylor and Francis; 1934.

13. Nagpal BN, Sharma VP. Survey of mosquito fauna of northeastern region of India. Indian J Malariol. 1987;24:143-9.

14. Christopher SR. The fauna of British India, including Ceylon and Burma, Diptera, Volume IV. New Delhi: Today and Tomorrow's Printers and publishers; 1933

15. Khan SA, Dutta P, Chowdhury P, Borah J, Topno R, Mahanta J. Coinfection of arboviruses presenting as Acute Encephalitis Syndrome. J Clin Virol. 2011:51(1):5-7.

16. Hall T. BioEdit version 7.0. 0. Distributed by the author. 2004. website: www. mbio.ncsu.edu/BioEdit/bioedit.html. Accessed 20 Dec 2013.

17. Kumar S, Stecher G, Tamura K. MEGA7: Molecular Evolutionary Genetics Analysis version 7.0 for bigger datasets. Mol Biol Evol. 2016:msw054. doi:10. 1093/molbev/msw054
18. Clarke DH, Casals J. Techniques for hemagglutination and hemagglutination-inhibition with arthropod-borne viruses. Am J Trop Med Hyg. 1958;7(5):561-73.

19. Hirota J, Shimizu S, Shibahara T, Kobayashi S. Cross-reactivity of chicken antiJapanese encephalitis virus serum and anti-West Nile virus serum in serological diagnosis. J Vet Med Sci. 2012;74(11):1497-9.

20. Chiang CL, Reeves WC. Statistical estimation of virus infection rates in mosquito vector populations. Am J Trop Med Hyg. 1962;75:377.

21. Khan SA, Narain K, Handique R, Dutta P, Mahanta J, Satyanarayana K, Srivastava VK. Role of some environmental factors in modulating seasonal abundance of potential Japanese encephalitis vectors in Assam, India. Southeast Asian J Trop Med Public Health. 1996;27:382-91.

22. Chancey C, Grinev A, Volkova E, Rios M. The global ecology and epidemiology of West Nile virus. BioMed Res. Int. 2015. http://dx.doi.org/10. 1155/2015/376230. Accessed 16 Aug 2016.

23. Peiris JSM, Amerasinghe FP. West Nile fever. In: Beran GW, Steele JH, editors. Handbook of zoonoses. Section B: Viral. 2nd ed. Boca Raton (FL): CRC Press; 1994. p. 139-48.

24. Maquart M, Boyer S, Rakotoharinome VM, Ravaomanana J, Tantely ML Heraud JM, Cardinale E. High prevalence of West Nile virus in domestic birds and detection in two new mosquito species in Madagascar. PLoS One 2016:11(1):e0147589.

25. Akhter R, Hayes CG, Baqar S, Reisen WK. West Nile virus in Pakistan. III. Comparative vector capability of Culex tritaeniorhynchus and eight other species of mosquitoes. Trans R Soc Trop Med Hyg. 1982;76(4):449-53.

26. Mishra AC, Jadi RS, Paramasivan R, Mourya DT. Antigen distribution pattern of West Nile virus in Culex tritaeniorhynchus, Culex vishnui and Culex pseudovishnui mosquitoes. J Comm Dis. 2001;33(3):174-9.

27. Reuben R, Thenmozhi V, Samuel PP, Gajanana A, Mani TR. Mosquito blood feeding patterns as a factor in the epidemiology of Japanese encephalitis in southern India. Am J Trop Med Hyg. 1992;46(6):654-63.

28. Bhattacharyya DR, Handique R, Dutta LP, Dutta P, Doloi P, Goswami BK, et al. Host feeding patterns of Culex vishnui sub group of mosquitoes in Dibrugarh district of Assam. J Comm Dis. 1994;26(3):133-8

29. Garcia-Rejon JE, Blitvich BJ, Farfan-Ale JA, Loroño-Pino MA, Chim WC, FloresFlores LF, et al. Host-feeding preference of the mosquito, Culex quinquefasciatus, in Yucatan State, Mexico. J Insect Sci. 2010;10(32):1-2.

30. Bondre VP, Jadi RS, Mishra AC, Yergolkar PN, Arankalle VA. West Nile virus isolates from India: evidence for a distinct genetic lineage. J Gen Virol. 2007; 88(3):875-84.

31. Weingartl HM, Drebot MA, Hubálek Z, Halouzka J, Andonova M, Dibernardo A, et al. Comparison of assays for the detection of West Nile virus antibodies in chicken serum. Can J Vet Res. 2003;67(2):128.

32. Mishra N, Kalaiyarasu S, Nagarajan S, Rao MV, George A, Sridevi R, et al. Serological evidence of West Nile virus infection in wild migratory and resident water birds in eastern and northern India. Comp Immunol Microbiol Infect Dis. 2012;35(6):591-8.

33. Fall AG, Diaïté $A$, Seck MT, Bouyer J, Lefrançois $T$, Vachiéry $N$, et al. West Nile virus transmission in sentinel chickens and potential mosquito vectors, Senegal river delta, 2008-2009. Int J Environ Res Publ Health. 2013;10(10):4718-27.

34. Ergunay K, Gunay F, Kasap OE, Oter K, Gargari S, Karaoglu T, et al. Serological, molecular and entomological surveillance demonstrates widespread circulation of West Nile virus in Turkey. PLoS Negl Trop Dis. 2014;8(7):e3028. 